\title{
Removal of Dye in Wastewater by Adsorption- Coagulation Combined System with Hibiscus sabdariffa as the Coagulant
}

\author{
Ho Nicholas Jian Hoong ${ }^{1}$, and Nurhazwani Ismail ${ }^{1, *}$ \\ ${ }^{1}$ School of Engineering, Faculty of Built Environment, Engineering, Technology \& Design, Taylor's \\ University, Subang Jaya, Selangor DE, Malaysia
}

\begin{abstract}
The conventional process to treat dye wastewater is the physicochemical treatment such as coagulation, flocculation and adsorption process. A new approach has been demonstrated to treat Congo red dye wastewater, which is the adsorption-coagulation hybrid process. Natural coagulant extracted from Hibiscus sabdariffa seeds is used as the coagulant while activated carbon is used as the adsorbent in this case study. The objective of this experiment is to study the significant factors that will affect the efficiency of dye removal. Then, the optimum conditions for the hybrid process is determined using Respond Surface Methodology (RSM). The variables are $\mathrm{pH}$, initial dye concentration, coagulant dosage and adsorbent dosage while the response of experiment is the dye removal percentage. A three-level and four-variable Box-Behnken design (BBD) is used for the RSM. A total of 27 sets of experimental results is required to determine the optimum conditions. Jar test is used to conduct the experiment with the addition of coagulant and adsorbent simultaneously. Based on the regression model analysis and ANOVA, the highly significant factors that contribute to the dye removal efficiency through adsorption-coagulation hybrid process are $\mathrm{pH}$ of solution and initial dye concentration. The RSM results shows that the optimised process parameters for adsorption-coagulation hybrid process with Hibiscus sabdariffa seeds as the coagulant and activated carbon as the adsorbent are $\mathrm{pH} 2$, initial dye concentration of $385 \mathrm{ppm}$, coagulant dosage of $209 \mathrm{mg} / \mathrm{L}$ and adsorbent dosage of $150 \mathrm{mg} / \mathrm{L}$. The dye removal reaches up to $96.67 \%$ under optimum parameters.
\end{abstract}

\section{Introduction}

Synthetic dyes are commonly used in many industries, such as textile, paper, plastic, ink cartridge and paint manufacture factories. During the washing and finishing stage in the manufacture process, they consume and discharge a huge amount of dye contaminated water. Based on research studies, it is estimated that 280,000 tons of textile dyes are

*Corresponding author: nurhazwani.ismail@taylors.edu.my 
discharged annually in the textile industry as effluent worldwide, ranking the first place in the usage of dyes among various industries [1]. Direct discharge of dye wastewater into the environment can be hazardous since synthetic dyes contain carcinogenic substances and heavy metals such as chromium $(\mathrm{Cr})$, lead $(\mathrm{Pb})$ and copper $(\mathrm{Cu})$ [2].

Most dyes are synthetic compounds with complex, highly-branched aromatic molecular structures [3]. Thus, dye wastewater is very resistant to biodegradation treatment process. The most conventional way of treating it is the physicochemical treatment. This method involves the coagulation and flocculation process which use up various coagulants such as alum, lime and ferric [4]. Chemical coagulants are capable of dissociating polyelectrolytes when in solution. The polyelectrolytes will neutralise the negatively charged dye molecules to form particle-polymer-particle complexes [4]. These contaminants will be precipitated in the form of chemical sludge when the treated water is further added with flocculants. However, the generated sludge contains a considerable amount of chemical residue such as iron and aluminium salts. These components are hazardous to human health and possess environmental impact. According to [5], aluminium-based coagulants attribute the development of Alzheimer's disease in human beings. Thus, there is an emerging trend in wastewater treatment industry using natural coagulants such as Moringa oleifera, Strychnos potatorum (Nirmali), Cactus opuntia etc [6]. Natural coagulants possess a few crucial advantages compared to chemical coagulants, such as environmentally friendly (sustainable and biodegradable), toxic-free and safer for application.

The usage of Hibiscus sabdariffa seeds as natural coagulants was first reported to clarify high turbidity water (above 300 NTU) in the Indian Journal of Environmental Health, 1974. The chemical polyelectrolyte is substituted by natural polyelectrolyte in the form of polysaccharide and proteins [7]. According to [8] and [6], these structures usually exhibit higher molecular weight compared to synthetic polymer. This greatly increase the unoccupied binding sites for the coagulation and partial adsorption process. Hibiscus sabdariffa seeds also contain coagulation proteins, mainly composed of cationic peptides, such as glutamic acid, aspartic acid and leucine [9]. Based on previous experiment case studies, the removal of dye using $H$. sabdariffa as coagulant typically ranges from 81.293.3\% $[6,10]$.

Adsorption process is also one of the most effective and low-cost treatment process to remove dyes in wastewater. The most conventional adsorbent used in industries is activated carbon. The efficiency of adsorption using activated carbon is relatively high due to its microporous structure, large surface area and high adsorption capacity [11]. In fact, it shows a stronger affinity for dyes removal compared to zeolite [11]. In this view, activated carbon can be potentially used as the adsorbent in this case study.

Till date, the combination compromising of more than one wastewater treatment process as a single system has shown to be more effective when treating wastewater [12]. Based on previous studies, adsorption-coagulation hybrid process has been used to treat real wastewater of complex dyes manufacturing plant and wastewater containing high concentration of humic and tannic acids $[12,13]$. Results show that hybrid process is proved to have $90 \%$ efficient in colloidal particles removal than coagulation as an individual process [13]. In this method, the coagulant and adsorbent are added simultaneously at one single unit for reaction. The hybrid process enhances and improves the performance of dye removal because the dye molecules are eliminated from the water, and not because of the partial decomposition of dye molecules, which can potentially lead to the formation of more harmful and toxic aromatic compounds [4]. Meanwhile, the activated carbon will adsorb the colour and odour in the solution and the forming sludge.

Thus, with respect to the study that has been done extensively, the hybrid process is used to treat Congo red dye solution with Hibiscus sabdariffa seeds as coagulant and 
activated carbon as adsorbent. Congo red is targeted in this study based on a few reasons. The molecular structure is also shown in Figure 1.

(i) Congo red is a typical benzidine-based azo dye. It is widely found in the effluent of industries. After releasing it to the environment, Congo red is metabolised to benzidine, a well-known carcinogen that can cause allergic diseases in human. Thus, an effective and feasible method is needed to treat the Congo red in the effluent [3].

(ii) The potentiality of adsorption-coagulation hybrid process of Congo red removal has not yet been studied. With this in view, in this present study, an attempt has been made to identify the coagulation potential of coagulation agent extracted from Hibiscus sabdariffa seeds with activated carbon, for the removal of Congo red dye from aqueous solution.<smiles>Nc1ccc(S(=O)(=O)O)c2ccc(N=Nc3ccc(-c4ccc(N=Nc5cc(S(=O)(=O)O)c6ccccc6c5N)cc4)cc3)cc12</smiles>

Fig. 1. Molecular structure of Congo red dye [14]

The objectives of conducting this research are to study the significant factors that will affect the performance of adsorption-coagulation hybrid process with Hibiscus sabdariffa seeds as coagulant and activated carbon as adsorbent on Congo red dye removal. Besides that, the optimum process parameters $(\mathrm{pH}$, initial dye concentration, coagulant dosage and adsorbent dosage will be determined using Respond Surface Methodology (RSM).

\section{Methodology}

In this research studies, quantitative method will be implemented extensively to collect objective measurements, then numerical, mathematical and statistical analysis of data will be conducted to verify and validate the results. Lastly, the results will be used for RSM to determine the optimised working parameters for the adsorption-coagulation hybrid process.

\subsection{Preparation of Synthetic Dye Wastewater}

The stock solution is prepared by dissolving 1 gram of Congo red dye powder in $1 \mathrm{~L}$ of distilled water. Theoretically, the concentration of stock solution will be $1001 \mathrm{ppm}$ [14]. The stock solution is then diluted using distilled water to prepare the required concentration. The $\mathrm{pH}$ of dye solution is adjusted by adding $1.0 \mathrm{M} \mathrm{NaOH}$ solution and 1.0 $\mathrm{M} \mathrm{HCl}$ solution. Noted that the colour of Congo red changes from red to blue when inorganic acid is added into the solution. This is due to the resonance between charged canonical structures [15]. The $\mathrm{pH}$ value is monitored using a $\mathrm{pH}$ meter. Table 1 simply summarise the physicochemical properties of Congo red dye.

Table 1. Physicochemical properties of Congo red

\begin{tabular}{|c|c|}
\hline Parameter & Value (unit) \\
\hline Molecular Weight & $696.66 \mathrm{~g} / \mathrm{mol}$ \\
\hline
\end{tabular}




\begin{tabular}{|c|c|}
\hline Molecular Formula & $\mathrm{C}_{3} \mathrm{H}_{22} \mathrm{~N}_{6} \mathrm{Na}_{2} \mathrm{O}_{6} \mathrm{~S}_{2}$ \\
\hline Absorption Maxima & $498 \mathrm{~nm}$ \\
\hline
\end{tabular}

\subsection{Preparation of Natural Coagulants}

\subsubsection{Pre-treatment of Hibiscus sabdariffa Seeds}

Hibiscus sabdariffa flowers are collected and the seeds are removed manually from their dried capsules. The seeds are quickly washed with distilled water to remove any fibrous traces and tower dried. The clean seeds are then dried in an oven at $60^{\circ} \mathrm{C}$ for 2 hours to preserve the protein in the seed. Drying temperature higher than $60^{\circ} \mathrm{C}$ will cause denature of the proteins [16].

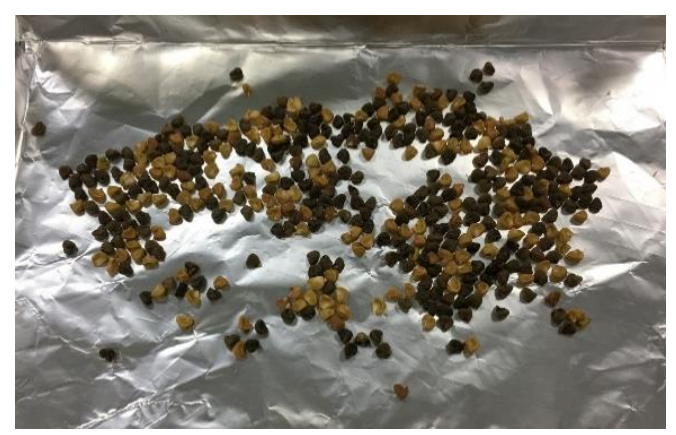

Fig. 2. Dried H. sabdariffa seeds

\subsubsection{Extraction of Coagulating Agent}

In this present work, sodium chloride solution is selected to be the extraction agent. since it can be obtained easily. During the extraction, the interaction between the peptides and the molecules of sodium chloride produces H-bonds with the adjacent molecules. The peptides will dissolve in the solution when the protein surface turns fully hydrophilic [17].

The concentration of sodium chloride solution was investigated. When the concentration of $\mathrm{NaCl}$ solution increases above $0.5 \mathrm{M}$, the binding sites of solvents are saturated and all protein fractions are extracted [18]. Research studies also show that there will be no significant changes of the extracted proteins when the concentration of $\mathrm{NaCl}$ solution increases from $0.6 \mathrm{M}$ to $1.0 \mathrm{M}$, [18]. Thus, $0.5 \mathrm{M}$ of $\mathrm{NaCl}$ solution is used as the solvent.

The seed is measured 0.5 gram and mixed with $100 \mathrm{~mL}$ of $0.5 \mathrm{M} \mathrm{NaCl}$ solution. The mixture is then blended in a household food blender for 2 minutes [10]. The mixture is sieved through a muslin cloth to remove any traces of seed residues. The filtrate is the extracted coagulating agent and it is milky in colour. The coagulating agent is used immediately after extraction to avoid deterioration.

\subsection{Preparation of Calibration Graph}

The stock solution is used to prepare various dye concentration solutions, which are 200, $400,600,800$ and $1000 \mathrm{ppm}$. The samples are transferred into the cuvettes and placed into the UV Spectrophotometer for the measurement of absorbance value. After taking the 
measurements, a calibration graph of absorbance value against dye concentration (ppm) is plotted. The calibration graph is used to determine the dye removal percentage of each treated samples. The dye removal percentage can be determined using Eq (1) as shown below [10].

$$
\text { Dye Removal }(\%)=\frac{A b s_{o}-A b s}{A b s_{o}} \quad \times \quad 100 \%
$$

Where $A b s_{o}$ and $A b s$ are the absorbance value before and after treatment process respectively.

\subsection{Design of Experiment}

\subsubsection{Jar Test}

Jar test apparatus is used to conduct the experiment in a few batches. The apparatus can accommodate a maximum of 6 beakers in a batch. Each batch will involve rapid mixing, slow mixing and sedimentation process. The dye solutions are stirred for 4 minutes at 100 rpm to allow floc formation. Then, the speed of mixer is reduced to $40 \mathrm{rpm}$ and agitating process is continued for 25 minutes for flocculation process. At the final stage, the precipitate is allowed to settle at the bottom of jar for 30 minutes [10].

\subsubsection{Factors}

There are four factors being manipulated in this experiment, which are $\mathrm{pH}$ of dye solution, initial dye concentration, coagulant dosage and adsorbent dosage. The range and level of each factor is summarised in Table 2.

Table 2. Range and level of each factor

\begin{tabular}{|c|c|c|c|c|c|}
\hline \multirow{2}{*}{ Variable } & Description & Code & Low (-1) & Central (0) & High (1) \\
\cline { 4 - 6 } & $\mathrm{pH}$ & $\mathrm{A}$ & 2 & 7 & 12 \\
\hline 2 & $\begin{array}{c}\text { Initial Dye } \\
\text { Concentration (ppm) }\end{array}$ & $\mathrm{B}$ & 200 & 400 & 600 \\
\hline 3 & $\begin{array}{c}\text { Coagulant Dosage } \\
(\mathrm{mg} / \mathrm{L})\end{array}$ & $\mathrm{C}$ & 120 & 260 & 400 \\
\hline 4 & $\begin{array}{c}\text { Adsorbent Dosage } \\
(\mathrm{mg} / \mathrm{L})\end{array}$ & $\mathrm{D}$ & 50 & 100 & 150 \\
\hline
\end{tabular}

\subsubsection{Response of Experiment}

The dye removal percentage is the response of the experiment. After the dye solution is being treated, the supernatant liquid is obtained without disturbing the precipitated flocs and transferred into a cuvette. It is then placed into UV spectrophotometer for the measurement of absorbance value. The dye removal percentage is then calculated using E.q (1). 


\subsubsection{Optimisation of Process Parameters using RSM}

RSM is a mathematical statistics technique method to build models, evaluate the complex relationships between independent factors and experiment response and to determine the optimum working conditions [19]. In this experiment, a three-level and four-variable BoxBehnken design (BBD) is demonstrated. In order to further analyses the optimum combination of working parameters, a 27-runs of experiment is conducted. The experimental results for the 27 sets of experiment are the input for aggression model analysis, ANOVA and RSM for optimisation purpose. The results and justifications are discussed at the part below.

\section{Results and Discussion}

\subsection{Model Fitting}

There are four variables tested in this experiment, which are $\mathrm{pH}$ of dye solution, initial dye concentration, coagulant dosage and adsorbent dosage. The relative contribution of each variables to the response (dye removal) is predicted from the regression coefficient in the fitted model [19]. The regression coefficient for dye removal is obtained using a statistical software, Minitab 18.0 by least square method. Table 3 simply summarises the obtained result from the software.

Table 3. Predicted regression coefficient of the polynomial model for dye removal

\begin{tabular}{|c|c|c|c|c|}
\hline $\begin{array}{c}\text { Independent } \\
\text { Variable }\end{array}$ & $\begin{array}{l}\text { Regression } \\
\text { Coefficient }\end{array}$ & t-Value & $\mathrm{p}$-Value & Significant Level \\
\hline Constant & 1.07 & 0.47 & 0.650 & \\
\hline \multicolumn{5}{|l|}{ Linear } \\
\hline A & -46.040 & -39.986 & 0.000 & $* * *$ \\
\hline B & 4.526 & 3.931 & 0.002 & $* * *$ \\
\hline $\mathrm{C}$ & -1.866 & -1.620 & 0.131 & \\
\hline $\mathrm{D}$ & 2.422 & 2.103 & 0.057 & \\
\hline \multicolumn{5}{|l|}{ Square } \\
\hline$A * A$ & 51.274 & 29.687 & 0.000 & $* * *$ \\
\hline $\mathrm{B} * \mathrm{~B}$ & -4.678 & -2.709 & 0.019 & $* *$ \\
\hline $\mathrm{C}^{*} \mathrm{C}$ & 2.202 & 1.275 & 0.226 & \\
\hline $\mathrm{D} * \mathrm{D}$ & 1.055 & 0.611 & 0.553 & \\
\hline \multicolumn{5}{|c|}{ 2-Way Interaction } \\
\hline $\mathrm{A} * \mathrm{~B}$ & 5.375 & 2.695 & 0.019 & $* *$ \\
\hline$A^{*} \mathrm{C}$ & -0.926 & -0.464 & 0.651 & \\
\hline$A * D$ & 0.539 & 0.270 & 0.792 & \\
\hline $\mathrm{B}^{*} \mathrm{C}$ & -0.069 & -0.034 & 0.973 & \\
\hline$B * D$ & 0.258 & 0.130 & 0.899 & \\
\hline$C * D$ & -0.593 & -0.297 & 0.771 & \\
\hline
\end{tabular}


Table 4. Model Summary

\begin{tabular}{ccc}
\hline $\mathrm{R}^{2}$ & $\mathrm{R}^{2}$ (adjusted) & $\mathrm{R}^{2}$ (predicted) \\
\hline $99.57 \%$ & $99.06 \%$ & $97.56 \%$ \\
\hline
\end{tabular}

Based on the analysis, the $\mathrm{pH}$ of $\mathrm{CR}$ solution (A), initial dye concentration (B) and second-order effect of $\mathrm{pH}\left(\mathrm{A}^{*} \mathrm{~A}\right)$ are the highly significant variables on dye removal. Theses independent variables have $p$-values smaller below $0.01(\mathrm{p}<0.01)$. Besides that, the second-order effect of initial dye concentration $\left(\mathrm{B}^{*} \mathrm{~B}\right)$ and the interaction of $\mathrm{pH}$ and dye concentration $\left(\mathrm{A}^{*} \mathrm{~B}\right)$ are significant on dye removal. Both of the variables have $\mathrm{p}$-values below $0.05(\mathrm{p}<0.05)$. A quadratic polynomial equation that describes the behaviour of dye removal to optimise the process can be determined from the regression coefficients of all the significant factors. The regression equation in term of coded variables is shown below.

$$
\mathrm{Y}_{2}=-46.040 \mathrm{~A}+4.526 \mathrm{~B}+51.274 \mathrm{~A}_{2}-4.678 \mathrm{~B}_{2}+5.375 \mathrm{AB}
$$

Coefficient of determination $\left(\mathrm{R}_{2}\right)$ is a measurement on how close the collected data are to the fitted regression line. It simply describes how well the model fits the data. Meanwhile, adjusted coefficient of determination (adjusted $R_{2}$ ) is an adjustment for $R_{2}$ to include the number of variables in a data set [19].

The analysis shows a $\mathrm{R}_{2}$ value of $99.57 \%$. This indicates that $99.57 \%$ of the total variation is explained by the model and the remaining $0.43 \%$ of the variation is unexplained. The adjusted $\mathrm{R}_{2}$ is determined to be $99.06 \%$ and is in good agreement with the $\mathrm{R}_{2}$. If a new set of data is fitted to the model for dye removal analysis, it shows $99.06 \%$ similar value with the $R_{2}$. Thus, the second-order regression model obtained for dye removal is satisfactory and E.q. (4) is fitted to represent the model.

\subsection{Analysis of Variance (ANOVA)}

Next, the fitted models obtained from section 3.1 will be further discussed by diagnostic checking. Table 5 shows the extracted results obtained from Minitab 18.0.

Table 5. ANOVA of the factors as linear, square and interaction on the effect dye removal

\begin{tabular}{cccccc}
\hline & & & Mean & & \\
Source & Degree of Freedom & Sum of Square & Square & F-Value & P-Value \\
\hline Model & $\mathbf{1 4}$ & $\mathbf{4 3 8 5 7 . 3}$ & $\mathbf{3 1 3 2 . 7}$ & $\mathbf{1 9 6 . 9 1 0}$ & $\mathbf{0 . 0 0 0}$ \\
Linear & 4 & 25794.5 & 6448.6 & 405.341 & 0.000 \\
Square & 4 & 17941.0 & 4485.2 & 281.929 & 0.000 \\
2-Way Interaction & 6 & 121.8 & 20.3 & 1.276 & 0.338 \\
Error & $\mathbf{1 2}$ & $\mathbf{1 9 0 . 9}$ & $\mathbf{1 5 . 9}$ & & \\
Lack-of-Fit & 10 & 183.7 & 18.4 & 5.085 & 0.175 \\
Pure Error & 2 & 7.2 & 3.6 & & \\
\hline Total & $\mathbf{2 6}$ & $\mathbf{4 4 0 4 8 . 2}$ & & & \\
\hline
\end{tabular}

The results of ANOVA test indicate that the regression model for the data on dye removal is highly significant as the $p$-value is small $(p<0.01)$. The $p$-value of LOF for this model is large ( $p>0.05)$, this shows that the LOF is insignificant. According to [35], the sum of square due to pure error (SSPE) measures the inherent variability of repeated 
measurements which cannot be explained by any model. However, a small value of pure error is still preferred. In this model, the pure error of is very small, which is $7.2 \%$.

In short, the ANOVA test shows that the regression model is fitted to describe the actual behaviours of dye removal based on the relationships of independent variables and thus Eq. (4) is able to represent the model. Th interaction between variables for dye removal is essential and is discussed below.

\subsection{Contour Plots and Optimisation of Parameters}

The model fitting analysis and ANOVA test as shown in section 3.1 and 3.2 have clearly illustrated the relationships between the independent variables and response. Thus, RSM method can be used to evaluate the optimisation of process parameters. The regression model analysis has shown that the significant interaction between variables are $\mathrm{A}$ : $\mathrm{pH}$ and B: Initial dye concentration. The relationships can be further illustrated in the threedimensional respond surface plot and contour plot, from Figure 3 to 5 .

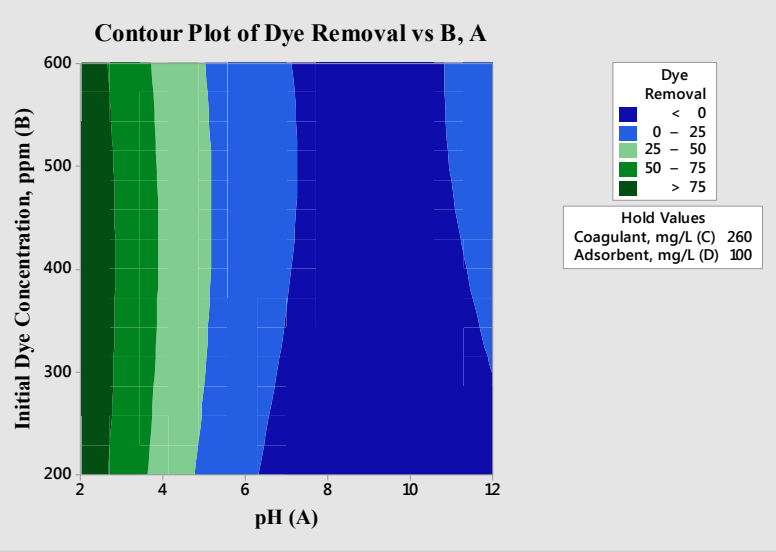

Fig. 3. Contour and respond surface plot of dye removal against $\mathrm{pH}$ and initial dye concentration

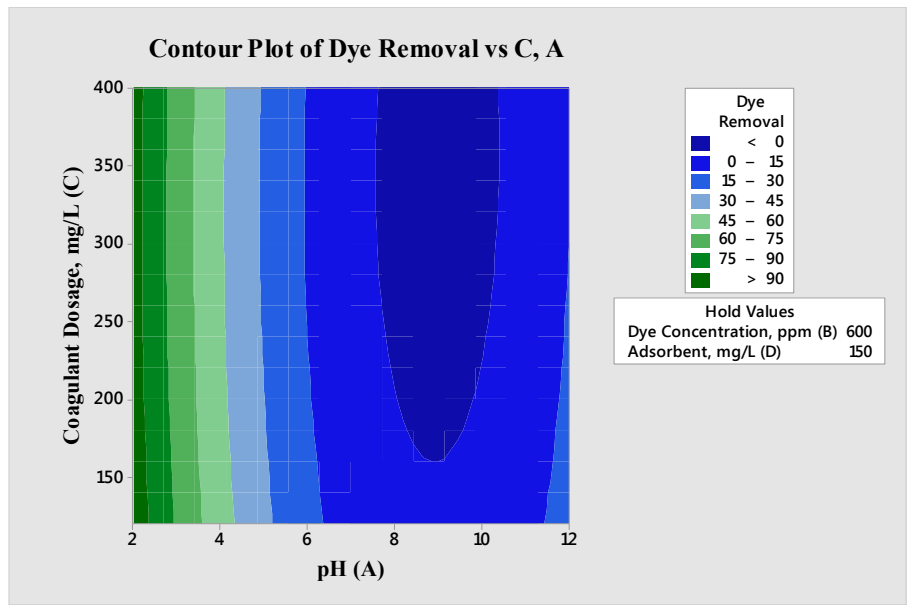

Fig. 4. Contour and respond surface plot of dye removal against $\mathrm{pH}$ and coagulant dosage 


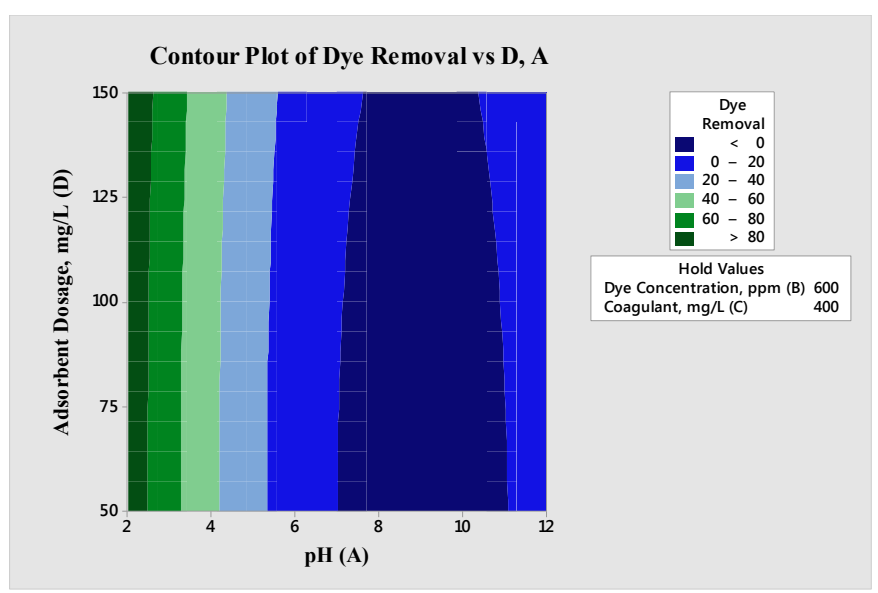

Fig. 5. Contour and respond surface plot of dye removal against $\mathrm{pH}$ and adsorbent dosage

The optimisation of the process variables was analysed using the response optimiser function in Minitab 18.0. The optimum conditions for the adsorption-coagulation hybrid process on dye removal are $\mathrm{pH} 2$, initial dye concentration of $385 \mathrm{ppm}$, coagulant dosage of $209 \mathrm{mg} / \mathrm{L}$ and adsorbent dosage of $150 \mathrm{mg} / \mathrm{L}$. With these optimum process parameters, the predicted dye removal percentage fits up to $96.67 \%$. Meanwhile, to further validate the predicted optimised conditions, an experiment using the stated values of variables was conducted and the experimental result shows a $98.71 \%$ of dye removal. Thus, the obtained optimised combination of process parameters is accepted.

\subsubsection{Influence of $\mathrm{pH}$ on Dye Removal}

Since natural coagulants are used in this case study, the $\mathrm{pH}$ is manipulated from 2 to 12 during the adsorption-coagulation hybrid process [10]. From the contour plot shown in Figure 3, the highest range of dye removal is established when the $\mathrm{pH}$ is between 2 and 3. This shows that acidic condition is favourable for Hibiscus sabdariffa seeds to perform its coagulation process. Conversely, the dye removal is reduced significantly when the $\mathrm{pH}$ increases from 6 to 12. Based on [9], the coagulant protein extracted from Hibiscus sabdariffa seeds consist of glutamic acid (27\%) and aspartic acid (11\%), both are the cationic amino group. When the coagulation condition is acidic, it further enhances the positively-charged environment by increasing the density of positive charges $(\mathrm{H}+)$ around the coagulants hydrolysates. Charge neutralisation and complex reaction between the coagulant proteins and dissociated organic compounds of Congo red dominate the coagulation mechanism [20]. At the isoelectric point, the surface colloid particle is electroneutral and the combined effect of bridging and charge neutralisation results in higher dye removal efficiency [20]. This may explain for the coagulants to achieve optimum dye removal effect at $\mathrm{pH} 2$ to 3.

According to [16], Hibiscus sabdariffa seeds also contain anionic peptides Under neutral and alkaline conditions, the dye removal percentage is rather low. This is because not all colloid particles will coprecipitate with the coagulant hydrolysates. In fact, most of the colloid particles and organic compounds of dyes merely absorbed on the surface of coagulants under neutral conditions when they collide with each other [20]. The absorption occurs due to weak chemical bonding but not attraction of charges. However, there is also a 
slight increase in dye removal when the dye solution reaches $\mathrm{pH} 12$. The possible reason is that alkaline condition (OH-) is favourable for the dissociation of small amount of coagulant protein, arginine. This coagulating agent coagulates the dye colloid thus increases the dye removal [9].

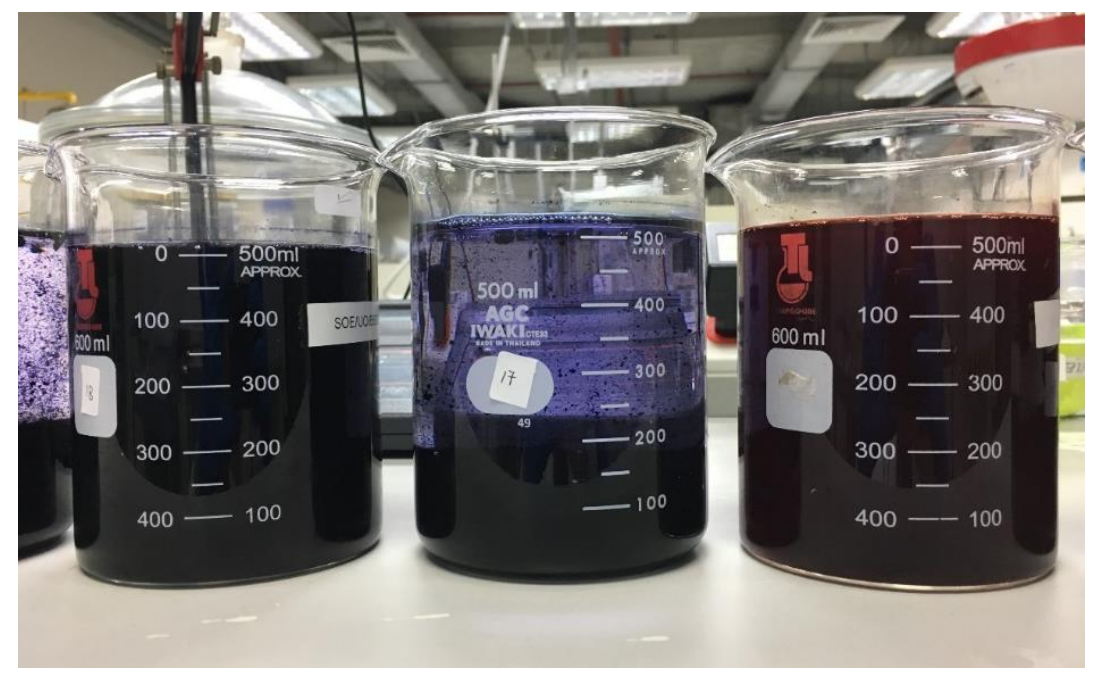

Fig. 6. Sample of $400 \mathrm{ppm}$ dye solutions - pH, coagulant dosage, adsorbent dosage (Left: 2, 120, 100; Centre: 2, 260, 50; Right: 7, 260, 150)

\subsubsection{Influence of Initial Dye Concentration on Dye Removal}

From the aggression model analysis, the initial dye concentration is also tested to be one of the highly significant factors that will attribute the dye removal percentage. In this case study, the dye concentration is manipulated from $200 \mathrm{ppm}$ to $600 \mathrm{ppm}$.

From the contour plot shown in Figure 3, the dye removal increases when the dye concentration increases. As the dye concentration increases, there are more free dye colloid particles readily existed to form particle-protein-particle complexes with the coagulant and thus increases the dye removal efficiency [21]. However, according to [10], the dye removal will drop or remain unchanged when the dye concentration reaches a saturation point. At this point, the coagulating agent is said to be saturated, there is no free amino group with active site available to coagulate the colloid particles. Therefore, the dye removal percentage will drop or remain unchanged. In this case study, the dye concentration is said to be optimised at $385 \mathrm{ppm}$, which means beyond this indicated concentration, the dye removal does not increase significantly. However, Figure 2 shows that the dye removal continues to increase even the dye concentration exceeds $385 \mathrm{ppm}$. This is because dye removal is resulted from the adsorption of Congo red dyes onto the activated carbon surfaces. Thus, the dye removal increases up to $600 \mathrm{ppm}$ dye concentration.

\subsubsection{Influence of Coagulation Dosage on Dye Removal}

In this case study, the coagulant dosage extracted from Hibiscus sabdariffa seeds is tested from $120 \mathrm{mg} / \mathrm{L}$ to $400 \mathrm{mg} / \mathrm{L}$ [10]. As shown in Figure 4, the dye removal increases gradually from $120 \mathrm{mg} / \mathrm{L}$ to $400 \mathrm{mg} / \mathrm{L}$ at $\mathrm{pH} 2$ to 3 . This is because as the cationic amino group increases, the peptides form more and stronger hydrogen bonding with the aromatic 
hydroxyl groups on dye particles. When abundant of coagulative components are available, it also neutralises the charges found on the surface of particles so that the particles can attract with one another more efficiently [5]. Thus, this explains for the increment of dye removal as the coagulant dosage increases.

However, it is also reported that the coagulation activity of Hibiscus sabdariffa seeds is decreased when the dosage reaches a certain point. This declination is caused by charge reversal which results the re-dispersion and re-stabilisation of dye colloidal particles due to overdosing of coagulant proteins [22]. However, this phenomenon will only occur when the coagulation dosage reaches up to $709 \mathrm{mg} / \mathrm{L}$ [23].

\subsubsection{Influence of Adsorption Dosage on Dye Removal}

The adsorbent dosage is manipulated from $50 \mathrm{mg} / \mathrm{L}$ to $150 \mathrm{mg} / \mathrm{L}$ [12]. As shown in Figure 5 , It can be seen that the increase in the adsorbent dosage increases the dye removal percentage of Congo red. This is because higher adsorbent dosage provides a greater surface area with more adsorption sites and thus increase the adsorption of dye.

The adsorption of dye particles at $\mathrm{pH} 2$ to 3 also shows higher removal percentage. When the density of positive charges in the solution increases, it avoids the adsorbents becoming more aggregated due to electrostatic interactions and steric repulsion force [12]. Thus, the stabilised adsorbent provides more adsorption sites. The excessive positive charges will also affect the surface charge of the adsorbent. As a result, the highly branched aromatic compounds of Congo red will gradually adsorb on the highly porous surface of the activated carbon and balances the dispersion status [24].

In short, $\mathrm{pH}$ and initial dye concentrations play an important role to maximise the performance of adsorption-coagulation hybrid process. The solution must be in between 2 to 3 so that the hybrid process can perform effectively (as shown in Figure 2 to 4 ).

The optimisation of the hybrid process and the interaction between process variables had been discussed above. The analysis shows that the dye removal can reach up to $96.67 \%$ when the $\mathrm{pH}$ of CR solution is 2 , initial dye concentration is $385 \mathrm{ppm}$, coagulant dosage is $209 \mathrm{mg} / \mathrm{L}$ and adsorbent dosage is $150 \mathrm{mg} / \mathrm{L}$.

\subsection{Summary}

Shah et al. had demonstrated the adsorption-coagulation process to remove pollutants in the textile dye wastewater from a manufacturing plant in Pakistan. In his research work, commercial coagulants such as ferric chloride $\left(\mathrm{FeCl}_{3}\right)$, ferrous sulphate $\left(\mathrm{FeSO}_{4}\right)$ and alum $\left[\mathrm{Al}_{2}\left(\mathrm{SO}_{4}\right)_{3}\right]$ are used for comparison purpose and bottom-based coal ash (BBCA) is used as an adsorbent in the hybrid process. According to the findings from Shah et al., the hybrid process was optimised when $1.68 \mathrm{~g} / \mathrm{L}$ of $\mathrm{FeCl}_{3}$ and $4 \mathrm{~g} / \mathrm{L}$ of BBCA was used to treat the dye effluent. The colour removal achieves up to $82 \%$, turbidity removal $84 \%$ and total suspended solid (TSS) 94\%.

The hybrid process performed in this current research study shows a $96.67 \%$ of dye removal. As compare with the colour removal reported from Shah et al., it shows that the properties of wastewater are important for removal efficiency. Shah et al. described the dye wastewater as effluent with high suspended organic compounds, because it consists of dyes, pigments, textile chemicals and binder emulsion. In contrast with the synthetic CR wastewater, the dye molecules are the only component presented in the solution, thus it can achieve high dye removal percentage.

In this research work, the optimum coagulant dosage is $209 \mathrm{mg} / \mathrm{L}$, which is much lower than $1.86 \mathrm{~g} / \mathrm{L}$. This is because of the composition of wastewater and the dosage of natural 
coagulant is normally lower than chemical coagulant [25]. Besides that, the optimum adsorbent dosage in this research work is $150 \mathrm{mg} / \mathrm{L}$, which is lower than $4 \mathrm{~g} / \mathrm{L}$. According to [11], the dosage of synthetic adsorbent such as activated carbon is normally lower than the dosage of natural adsorbent in water treatment process. This is because the manufacturing process of synthetic adsorbent which requires strict temperature and pressure control produces highly porous activated carbon. This greatly increase the adsorption surface area of activated carbon. Note that the dye molecules adsorbed on the surface of activated carbon is relatively small compared with the organic pollutants in real wastewater. Thus, the dosage of activated carbon is lower than the dosage BBCA.

Shah et al. had also reported that higher dosing of coagulant and adsorbent more than $1.68 \mathrm{~g} / \mathrm{L}$ and $4 \mathrm{~g}$ did not improve the removal efficiency in terms of the reduction of colour and concentration of pollutants. This is due to the occurrence of steady state condition with higher dosing of coagulant and adsorbent. This is true based on the analysis of the current experimental result. When the coagulant and adsorbent dosage reach $209 \mathrm{mg} / \mathrm{L}$ and 150 $\mathrm{mg} / \mathrm{L}$ respectively in the $\mathrm{CR}$ solution with dye concentration of $385 \mathrm{ppm}$, the removal efficiency will drop below $96.67 \%$.

Shah et al. also suggested that among the three coagulants used, the combination of alum-BBCA has the lowest removal efficiency, with $77 \%$ of colour removal, $79 \%$ of turbidity removal and $93 \%$ of TSS removal. This may be due to the $\mathrm{pH}$ of effluent that influence the coagulation activity of alum as lime is added into the water sample for $\mathrm{pH}$ maintenance. Based on [4], the optimum pH for alum is 5.3. Since lime is an alkaline, it will affect the performance of coagulation in the hybrid process and thus reduce the removal efficiency. In this research work, the analysis shows that the coagulation of $H$. sabdariffa seeds is efficient at $\mathrm{pH} 2$. Thus, it can remove the dye efficiently.

From this summary, it can be concluded that the adsorption-coagulation hybrid process with $H$. sabdariffa seeds as coagulant and activated carbon as adsorbent can potentially achieve the removal efficiency obtained from RSM if it is scaled up or used to treat real dye wastewater. The process condition must be optimised so that the interaction of adsorbent and coagulant with the pollutants can be improved and thus increase removal efficiency.

\section{Conclusion}

In conclusion, this case study shows that Hibiscus sabdariffa seeds are workable natural coagulants. It also serves as an alternative to remove Cong red dye wastewater in real practice. Based on the aggression model analysis and ANOVA, the highly significant factors that contribute to the dye removal efficiency through adsorption-coagulation hybrid process are $\mathrm{pH}$ of solution and initial dye concentration. The RSM results shows that the optimised process parameters for adsorption-coagulation hybrid process with Hibiscus sabdariffa seeds as the coagulant and activated carbon as the adsorbent are $\mathrm{pH} 2$, initial dye concentration of $385 \mathrm{ppm}$, coagulant dosage of $229 \mathrm{mg} / \mathrm{L}$ and adsorbent dosage of $50 \mathrm{mg} / \mathrm{L}$. The dye removal reaches up to $98.68 \%$ under optimum parameters.

\section{Acknowledgment}

The author would like to offer a token of appreciation to Ms. Nurhazwani Ismail, Ms. Nur Farihah A. Malek and Ms. Lithnes Kalaivani for their kind support throughout the research studies until it is successfully completed.

\section{References}


[1] B. Frindt, J. Mattusch, T. Reemtsma, A. G. Griesbeck, A. Rehorek, Multidimensional monitoring of anaerobic/aerobic azo dye based wastewater treatments by hyphenated UPLC-ICP-MS/ESI-Q-TOF-MS techniques, Environ. Sci. Pollut. Res., 24, 12, 10929-10938 (2017)

[2] A. Pirkarami, M. E. Olya, "Removal of dye from industrial wastewater with an emphasis on improving economic efficiency and degradation mechanism," J. Saudi Chem. Soc., 21, 179-186 (2017)

[3] C. Jiang, B. Fu, H. Cai, T. Cai, Efficient adsorptive removal of Congo red from aqueous solution by synthesized zeolitic imidazolate framework-8, Chem. Speciat. Bioavailab., 28, 1, 199-208 (2016)

[4] A. K. Verma, R. R. Dash, P. Bhunia, A review on chemical coagulation/flocculation technologies for removal of colour from textile wastewaters, J. Environ. Manage., 93, 1, 154-168 (2012)

[5] T. . V. K. Vijayaraghavan, G. Sivakumar, Application of Plant Based Coagulants for Waste Water Treatment, Int. J. Adv. Eng. Res. Stud., 1, 1, 88-92 (2011)

[6] C. P. Pise, S. A. Halkude, A New Technique for Purification of Water Using Natural Coagulant, Int. J. Eng. Technol., 6, 6, 2564-2572 (2015)

[7] C. Y. Yin, Emerging usage of plant-based coagulants for water and wastewater treatment, Process Biochem., 45, 9, 1437-1444 (2010)

[8] U. A.Y, I. T.S., The Role of Green Coagulants in Wastewater Treatment: A Review, Wastewater Remediat. Using Plant Tech.(2016)

[9] A. N. Jones, Investigating the potential of Hibiscus seed species as alternative water treatment material to the traditional chemicals (2006)

[10] M. Y. Yong, N. Ismail, Optimisation of Hibiscus sabdariffa as a natural coagulant to treat Congo red in wastewater, J. Eng. Sci. Technol., 11, 153-165 (2016)

[11] A. Bhatnagar, A. K. Minocha, Conventional and non-conventional adsorbents for removal of pollutants from water - A review, Indian J. Chem. Technol., 13, 3, 203217 (2006)

[12] C. Jung, N. Phal, J. Oh, K. H. Chu, M. Jang, Y. Yoon, Removal of humic and tannic acids by adsorption-coagulation combined systems with activated biochar, J. Hazard. Mater., 300, 808-814 (2015)

[13] A. Shah, A.K. Memon, A. Metlo, G. Peerzada, Simultaneous CoagulationAdsorption Process Optimization for the Treatment of Real Wastewater of Complex Dyes Manufacturing Plant, 45, 3, 506-513 (2013)

[14] G. Vijayaraghavan, S. Shanthakumar, E. E. Division, B. Sciences, Removal of Congo Red Dye Using a Natural Bio- Polymeric Coagulant, Int. Conf. Recent Adv. Chem. Environ. \&Energy Eng., 17, 1-5 (2014)

[15] B. Meroufel, O. Benali, M. Benyahia, Y. Benmoussa, M. A. Zenasni, Adsorptive removal of anionic dye from aqueous solutions by Algerian kaolin: Characteristics, isotherm, kinetic and thermodynamic studies, J. Mater. Environ. Sci., 4, 3, 482-491 (2013)

[16] S. M. N. Halimatul, I. Amin, N. Mohd-Esa, A. G. Nawalyah, M. Siti Muskinah, Protein quality of roselle (Hibiscus sabdariffa L.) seeds, Int. Food Res. J., 14, 2, 131-140 (2007)

[17] K. C. Duong-Ly, S. B. Gabelli, Salting out of proteins using ammonium sulfate precipitation, Methods Enzymol., 541, 85-94 (2014)

[18] S. Eldein, B. Ahmed, Some Physicochemical and Nutritional Studies on Karkade (Hibiscus sabdariffa) Seed Proteins, Rev. Lit. Arts Am (1998)

[19] T. Amir, N. Ismail, F. Alkarkhi et al., Optimization of Coagulation Process for Landfill Leachate Pre-Treatment Using Response Surface Methodology (RSM), J. Sustain. Dev., 2, 2, 159 (2009) 
[20] B. C. Cao, B. Y. Gao, C. H. Xu, Y. Fu, X. Liu, Effects of pH on coagulation behavior and floc properties in Yellow River water treatment using ferric based coagulants, Chinese Sci. Bull., 55, 14, 1382-1387 (2010)

[21] S. Shamsnejati, N. Chaibakhsh, A. R. Pendashteh, S. Hayeripour, "Mucilaginous seed of Ocimum basilicum as a natural coagulant for textile wastewater treatment," Ind. Crops Prod., 69, 40-47 (2015)

[22] N. Fathinatul, R. Nithyanandam, Wastewater Treatment by using Natural Coagulant, 2nd Eureca, 2-3 (2014)

[23] C. Y. Yong, Removal of Congo red by Using Hibiscus sabdariffa for Coagulation and Flocculation Process (School of Engineering, Taylor's University, Malaysia, 2016)

[24] K. Zare et al., "A comparative study on the basis of adsorption capacity between CNTs and activated carbon as adsorbents for removal of noxious synthetic dyes: a review," J. Nanostructure Chem., 5, 2, 227-236 (2015)

[25] R. Sanghi, B. Bhattacharya, A. Dixit, and V. Singh, I. dasysperma seed gum: An effective natural coagulant for the decolorization of textile dye solutions, J. Environ. Manage., 81, 1, 36-41 (2006) 